\title{
Development of Synbiotic Litchi Juice Drink and its Physiochemical, Viability and Sensory Analysis
}

\author{
Prakash KS, Bashir K and Mishra V* \\ National Institute of Food Technology, Entrepreneurship and Management, Kundli, Haryana, India
}

\begin{abstract}
The study was carried out to evaluate the viability, physicochemical analysis and sensory analysis using fuzzy logic of synbiotic litchi juice drink containing probiotic $L$. casei 359 microencapsulated by spray drying using whey protein concentrate powder (WPCP) as wall material along with prebiotics inulin, gum acacia and oligofructose. The viable cell counts showed promising results for WPCP in combination with inulin, although, the cell count was higher than $10^{6} \mathrm{cfu} / \mathrm{ml}$ for all the juice drink samples. The microcapsules showed similar morphologies with partially collapsed spherical shape with concavities but no surface fissures. There was reduction in $\mathrm{pH}$ for the sample containing gum acacia as prebiotic. Rheological properties showed a non-Newtonian behaviour and Herschel-Buckley model was fitted best. Fuzzy analysis showed higher acceptance for the sample containing inulin as prebiotic based on the parameters of color, taste, aroma and mouthfeel.
\end{abstract}

Keywords: Whey protein concentrate; Prebiotics; Probiotics; L. casei; Inulin

\section{Introduction}

Development new functional foods containing probiotics has gained much attention during the past two decades. Probiotics are defined as live and active bacteria food supplements, the consumption of which in adequate amounts demonstrates better health benefits on the host over foods without probiotics [1]. Different health benefits are attributed to probiotics such as alleviation of lactose intolerance, treatment of different forms of diarrhoea, reduction in number and metabolic activity of gut pathogens, antioxidative potential $[2,3]$, In food, it has generally been recommended that probiotic bacteria must be present at a minimum level of $10^{6} \mathrm{CFU} / \mathrm{g}$ of food products [4] or $10^{7} \mathrm{CFU} / \mathrm{g}$ at point of delivery [5]. Dairy products such as yoghurt and fermented milk are considered suitable carriers of probiotics. However, with growing concerns over lactose intolerance and cholesterol level in milk, there is increasing trends for application of probiotics in nondairy products as well over the years [6-8]. Among many food products, fruit juices have been suggested to serve as good medium for probiotics [9]. Besides, fruit juices have the advantages of being vastly acceptable for consumption worldwide.

Fruit juices are appreciated for their refreshing flavour therapeutic value sand exotic appearance. Their therapeutic properties have been attributed to the presence of various phytochemicals and bioactive compounds as well as dietary nutrients viz. vitamins, fiber, minerals, etc. [10]. Fruit juices or drinks based on fruit juices can be an important carrier of probiotics providing functional properties of probiotics along with nutritional attributes they possess. Suomalainen et al. [11] suggested that mixing whey in orange juice improved the survival ability of L. rhamnosus E800 and Lc705 in the gastrointestinal tract. No adverse effects on intestinal function were observed during consumption of whey-based orange juice supplement with probiotics. Yoon et al. [12] reported the production of tomato juice containing probiotic using probiotication process. This process allowed probiotic bacteria to grow in fruit juices. They reported that fermented tomato juice might serve as a probiotic beverage for vegetarians or consumers allergic to dairy products. Fermentation of tomato juice using L. acidophilus LA 39 at $30^{\circ} \mathrm{C}$ for 72 hours provided the products containing higher than $10^{6}$ cfu $\mathrm{ml}^{-1}$ after storage for 4 weeks at $4^{\circ} \mathrm{C}$. Although the probiotication can provide a high number of cells above the benefit level in fruit juices, the sensory characteristics of the product may not be acceptable by the consumers [13]. Direct addition of probiotics in the product is one method to produce probiotic fruit juice. The survival of probiotics during storage is important. Information is required to validate the benefits of probiotics in the product. Krasaekoopt et al. [14] reported that the survival of probiotic bacteria, L. casei 01 and L. acidophilus TISTR 450, in commercial fruit juices during low temperature storage was higher than free cells by approximately 4 logs. To enhance survival of probiotics in fruit juices, microencapsulation of cultures is considered an important technique. The viabilities of microencapsulated probiotic bacteria among various types of fruit juices were not significantly different. Moreover, there were no changes in acidity of fruit juices during storage.

Litchi as a common fruit has been widely planted in Southeast Asia. Because of its attractive colour, unique flavour and delicious taste, litchi has been widely accepted by consumers. Due to the climatic requirements, it is grown mainly in China and India, both cumulatively contributing to about $90 \%$ of world litchi production. Because of its high moisture content and soft texture its shelf life is very short and thus is processed for juice production commercially. As there is increased trend in the shifting of simple food towards functional foods [15], it has motivated the food industries to develop new foods with functional properties. In the current research an attempt was carried out to study the feasibility of developing synbiotic litchi juice with whey protein concentrate as potential wall material for encapsulation of probiotic Lactobacillus casei 359, along with prebiotic materials including gum acacia, inulin and oligofructose.

*Corresponding author: Mishra V, National Institute of Food Technology Entrepreneurship and Management, Kundli, Haryana-131028, India, Tel: +91-1302281272; E-mail: vijendramishra.niftem@gmail.com

Received November 22, 2017; Accepted December 11, 2017; Published December 18, 2017

Citation: Prakash KS, Bashir K, Mishra V (2017) Development of Synbiotic Litchi Juice Drink and its Physiochemical, Viability and Sensory Analysis. J Food Process Technol 8: 708. doi: 10.4172/2157-7110.1000708

Copyright: (c) 2017 Prakash KS, et al. This is an open-access article distributed under the terms of the Creative Commons Attribution License, which permits unrestricted use, distribution, and reproduction in any medium, provided the original author and source are credited. 


\section{Materials and Method}

\section{Materials}

L. casei 359 culture was procured from National Dairy Research Institute (NDRI), Karnal, India. Ripened litchi (L. chinensis var Shahi) was procured from local wholesale market Azadpur, Delhi (India). Whey protein concentrate powder (WPCP) was purchased from Mahaan Proteins Ltd. India, gum acacia, inulin and oligofructose were procured from Himedia Laboratories Pvt. Ltd. Mumbai, India.

\section{Preparation of litchi juice}

The fruits were washed with clean water, peeled and destoned by hand. Juice was extracted from the pulp using table top juice extractor (Bajaj FX-10 Food Processor). The juice was then passed through muslin cloth for filtration. The juice was immediately placed into sterilized bottles, pasteurized, cooled and stored at $4^{\circ} \mathrm{C}$ till further treatment.

\section{Experimental plan}

Preparation of microencapsulated probiotic powder: L. casei 359 culture was activated by reconstituting in Lactobacillus MRS (deMan, Rogosa and Sharpe medium, Himedia) broth for 24 hours in an incubator shaker (G24, New Brunswick Scientific, NJ, USA) at $110 \mathrm{rpm}$ and $37^{\circ} \mathrm{C} .10 \mathrm{~mL}$ of the activated culture was transferred into $1 \mathrm{~L} \mathrm{MRS}$ broth for further growth overnight till it reached a cell concentration of approximately $10^{8}-10^{9} \mathrm{cells} / \mathrm{ml}$. The culture suspension was centrifuged (3-18 KS Sigma, Germany) at $8000 \mathrm{rpm}$ for $10 \mathrm{~min}$ at $4^{\circ} \mathrm{C}$. The supernatant was decanted and the residue obtained in each was used as probiotic culture in four different treatments, as described below:

$\mathrm{T}_{1}$ : Probiotic culture obtained as discussed above was mixed with $100 \mathrm{~g}$ WPCP in one litre distilled water.

$\mathrm{T}_{2}$ : Probiotic culture was mixed with $100 \mathrm{~g}$ WPCP and $20 \mathrm{~g}$ inulin (as prebiotic) in one litre distilled water.

$\mathbf{T}_{3}$ : Probiotic culture was mixed with $100 \mathrm{~g}$ WPCP and $20 \mathrm{~g}$ gum acacia (as prebiotic) in one litre distilled water.

$\mathbf{T}_{4}$ : Probiotic culture was mixed with $100 \mathrm{~g}$ WPCP and $20 \mathrm{~g}$ oligofructose (as prebiotic) in one litre distilled water.

All the samples were homogenized using ultra homogenizer (IKA $\mathrm{T} 18 \mathrm{D}$, Germany) at $10000 \mathrm{rpm}$ for $15 \mathrm{~min}$ followed by incubation at $37^{\circ} \mathrm{C}$ for $2 \mathrm{~h}$. The mixture was then spray dried (18 SMST, India) for microencapsulation at inlet temperature $165^{\circ} \mathrm{C}$ and outlet temperature $75^{\circ} \mathrm{C}$. The powders obtained were stored at $4^{\circ} \mathrm{C}$ till further use.

Probiotic litchi juice drink production: Probiotic Litchi juice drink was prepared by mixing juice with distilled water, sugar and microencapsulated probiotic powder in the ratio of $20: 60: 10: 10$ by weight respectively. A control was run in parallel containing juice, distilled water, sugar and WPCP at 20:60:10:10 by weight respectively. All the samples were analysed immediately after their production for initial microbial populations according to the methodology as described in section.

\section{Scanning electron microscopy of probiotic powder}

The morphological properties of microencapsulated powder were observed by scanning electron microscopy. The samples were placed on an adhesive tape attached to a circular aluminium specimen stub and coated with a thin layer of gold. The samples were photographed at an accelerating potential of $10 \mathrm{kV}$ using scanning electron microscope (JEOL JSM-7500, JEOL Ltd, Tokyo Japan).

\section{Rheological properties of juice drink}

The rheological measurements were carried out using Rheometer (Anton Paar MCR 102, Austria) with cylindrical geometry (cup diameter: $48 \mathrm{~mm}$, bob diameter: $45 \mathrm{~mm}$ ). The flow curves at different temperatures, $10^{\circ}$ and $20^{\circ} \mathrm{C}$ were obtained in the range of shear rate of 0.01-100 s $\mathrm{s}^{-1}$. The data obtained was fitted with Power Law (Eq. 1) and Herschel-Bulkley model (Equation 2).

$$
\begin{aligned}
& \tau=K^{\dot{\gamma}_{n}} \\
& \tau=\tau_{0}+K^{\dot{\gamma}_{n}}
\end{aligned}
$$

Where, $\tau$ is shear stress $(\mathrm{Pa}), \tau_{0}$ is yield stress $(\mathrm{Pa}), \dot{\gamma}$ shear rate $\left(\mathrm{s}^{-1}\right), \mathrm{K}$ is consistency index $\left(\mathrm{Pa} \cdot \mathrm{s}^{\mathrm{n}}\right)$ and $\mathrm{n}$ is flow behaviour index (dimensionless) signifying the extent of deviation from Newtonian behaviour.

\section{Physicochemical properties of probiotic litchi juice drink}

The physicochemical properties of the probiotic juice were performed according to AOAC, methods. The $\mathrm{pH}$ of the samples was determined with a digital $\mathrm{pH}$ meter (Lab India) at $22 \pm 2^{\circ} \mathrm{C}$. Total soluble solids of the samples were determined by digital Refractrometer (Atago rx-7000i) at $20^{\circ} \mathrm{C}$. Water activity was measured by digital water activity meter (Model-3TE, AQUA labs). Colour of the samples was determined by Colorimeter (Hunter Lab D25 LT) on the basis of $\mathrm{L}^{*}, \mathrm{a}^{*}$ and $b^{\star}$ values. The equipment was calibrated each time the treatment changed using white colour standard tile.

Fourier Transform Infrared (FTIR) spectroscopy of the probiotic juice drink was carried out by (Agilent Technologies Cary 630). A few drops of each sample were positioned in contact with attenuated total reflectance (ATR) plate. The ATR plate was carefully cleaned in situ by scrubbing with propanol and dried with soft tissue before filling in with the next sample. The plate cleanliness was verified by collecting a background spectrum. The spectra were recorded as percentage Transmittance within the range of $600-4000 \mathrm{~cm}^{-1}$.

\section{Enumeration of L. casei 359}

For enumeration of L. casei 359 , serial dilution was performed, and $1 \mathrm{ml}$ aliquots of each dilution were transferred to sterile MRS agar petri plates in triplicates. The plates were incubated under aerobic conditions at $37^{\circ} \mathrm{C}$ for 48 hours.

\section{Evaluation of overall sensory score}

Sensory evaluation of probiotic litchi juice drink: Sensory evaluation of probiotic litchi juice drink was done using fuzzy logic technique with 11 numbers of judges of the student and Faculty of the National Institute of Food Technology Entrepreneurship and Management Kundli aged between 23 to 50 years. The panellist was instructed to use fuzzy logic scale ( $1=$ Not satisfactory, $5=$ excellent) to evaluate the acceptability of sensory attributes such as colour, taste aroma and mouth feel. Judges were asked to give their response after tasting probiotic litchi juice and give tick mark to each sample as per their own feeling.

Fuzzy analysis of sensory data: The major steps involved in fuzzy modelling of sensory evaluation data were: (i) calculation of overall sensory scores of litchi juice samples in the form of triplets; (ii) estimation of membership function on standard fuzzy scale; (iii) computation of overall membership function on standard fuzzy scale; (iv) estimation of similarity values and ranking of the litchi juice samples; and (v) quality attributes ranking of litchi juice samples in 
general. The responses were analyzed using similarity analysis [16-24]. A program was coded in MATLAB for the calculation of all the abovementioned steps.

\section{Statistical analysis}

Experiments were conducted in triplicates and mean values were taken with calculation of standard deviations. The data were subjected to one-way analysis of variance (ANOVA) with a significance level of $5 \%$ and Duncan's test was applied to determine the differences between the means using the commercial statistical packages (SPSS, Inc, Chicago, IL, USA).

\section{Results and Discussion}

\section{Powder properties}

The probiotic powder was analysed by scanning electron microscopy (Figure 1). All the powders displayed a partially collapsed spherical shape with concavities. There were no evidences of the surface fissures or rupture of the microspheres which confirms good structural integrity and suggests low gas (water vapour and oxygen) permeability [25]. It also helps to withstand the mechanical forces associated with the expansion and ballooning during spray drying [26]. In addition, absence of free surface bacteria indicated good encapsulating performance of the powders. The microstructural aspects of the spray dried products are critically influenced by several parameters such as drying rates, composition, viscosity of the drying carrier aliquots and the atomisation process [27]. The $\mathrm{T}_{4}$ samples containing oligofructose resulted in more aggregated particles which was due to stickiness caused by low glass transition temperatures of oilogofructose [26-29].

\section{Probiotic litchi juice drink properties}

The colour of the probiotic litchi juice is given in Table 1 . The $\mathrm{L}^{\star}$ value changed significantly as the prebiotic was changed. The highest value of $\mathrm{L}^{*}$ was found as $69.19 \mathrm{in}$ sample $\mathrm{T}_{2}$, containing $\mathrm{WPCP}$ and inulin followed by $\mathrm{T}_{4}$ containing WPCP and oligofructose having a value of 59.12. The $L^{\star}$ value did not change significantly between control and $T_{3}$ (containing WPCP and gum acacia). The minimum $\mathrm{L}^{\star}$ value was found in $\mathrm{T}_{1}$ containing WPCP only. The increase in the values of lightness for $\mathrm{T}_{2}$ and $\mathrm{T}_{4}$ can be attributed to the more lightness in the prebiotics (inulin and oligofructose) added. The $\mathrm{a}^{*}$ values changed significantly within the samples. The highest $\mathrm{a}^{*}$ value was found in $\mathrm{T}_{3}$ because of the gum acacia. The positive $\mathrm{a}^{*}$ values that indicate more redness while

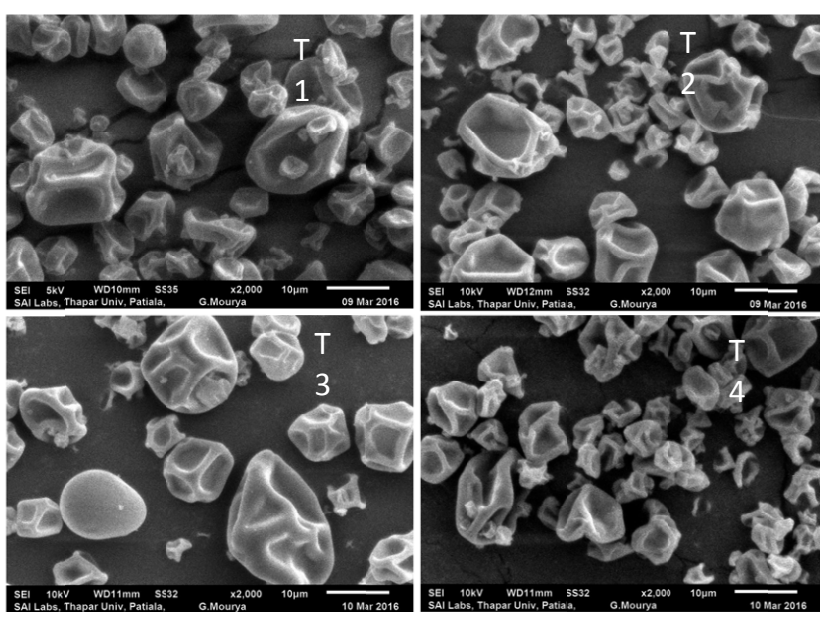

Figure 1: SEM of microencapsulated probiotic powder.

\begin{tabular}{|c|c|c|c|c|c|c|c|}
\hline Sample & $\mathbf{L}^{*}$ & $a^{*}$ & $\mathbf{b}^{*}$ & TSS & $\mathrm{pH}$ & aw & $\begin{array}{l}\text { TPC (log } \\
\text { (cfu/ml) }\end{array}$ \\
\hline $\mathrm{T}_{1}$ & $\begin{array}{c}45.82 \pm \\
1.29^{a}\end{array}$ & $\begin{array}{c}-0.59 \pm \\
0.09^{c}\end{array}$ & $\begin{array}{c}4.52 \pm \\
0.84^{b}\end{array}$ & $\begin{array}{c}20.71 \pm \\
0.04^{\mathrm{a}}\end{array}$ & $\begin{array}{l}5.38 \pm \\
0.24^{\mathrm{ab}}\end{array}$ & $\begin{array}{c}0.99 \pm \\
0.00^{\mathrm{a}}\end{array}$ & $\begin{array}{l}6.9 \pm \\
0.51^{\mathrm{b}}\end{array}$ \\
\hline $\mathrm{T}_{2}$ & $\begin{array}{c}69.19 \pm \\
0.57^{\mathrm{d}}\end{array}$ & $\begin{array}{c}-3.12 \pm \\
0.41^{\mathrm{a}}\end{array}$ & $\begin{array}{l}1.49 \pm \\
0.83^{a}\end{array}$ & $\begin{array}{c}21.37 \pm \\
0.59^{\mathrm{b}}\end{array}$ & $\begin{array}{c}5.25 \pm \\
0.04^{\mathrm{a}}\end{array}$ & $\begin{array}{c}0.98 \pm \\
0.01^{\mathrm{a}}\end{array}$ & $\begin{array}{l}8.12 \pm \\
0.35^{b}\end{array}$ \\
\hline $\mathrm{T}_{3}$ & $\begin{array}{c}48.55 \pm \\
1.85^{\mathrm{b}}\end{array}$ & $\begin{array}{l}0.07 \pm \\
0.01^{d}\end{array}$ & $\begin{array}{c}6.60 \pm \\
1.4^{\mathrm{c}}\end{array}$ & $\begin{array}{c}20.82 \pm \\
0.02^{\mathrm{a}}\end{array}$ & $\begin{array}{c}4.97 \pm \\
0.35^{\mathrm{a}}\end{array}$ & $\begin{array}{c}0.99 \pm \\
0.00^{\mathrm{a}}\end{array}$ & $\begin{array}{c}7.26 \pm \\
0.66^{b}\end{array}$ \\
\hline $\mathrm{T}_{4}$ & $\begin{array}{c}59.12 \pm \\
0.09^{c}\end{array}$ & $\begin{array}{l}-2.14 \pm \\
0.02^{b}\end{array}$ & $\begin{array}{c}0.26 \pm \\
0.14^{a}\end{array}$ & $\begin{array}{c}20.75 \pm \\
0.08^{\mathrm{a}}\end{array}$ & $\begin{array}{c}5.79 \pm \\
0.00^{\mathrm{b}}\end{array}$ & $\begin{array}{c}0.99 \pm \\
0.00^{\mathrm{a}}\end{array}$ & $\begin{array}{c}7.42 \pm \\
0.79^{b}\end{array}$ \\
\hline Control & $\begin{array}{c}49.12 \pm \\
0.85^{\mathrm{b}}\end{array}$ & $\begin{array}{c}-0.13 \pm \\
0.02^{d}\end{array}$ & $\begin{array}{c}7.12 \pm \\
0.75^{c}\end{array}$ & $\begin{array}{c}20.93 \pm \\
0.01^{\mathrm{ab}}\end{array}$ & $\begin{array}{c}5.84 \pm \\
0.11^{\mathrm{b}}\end{array}$ & $\begin{array}{c}0.99 \pm \\
0.00^{\mathrm{a}}\end{array}$ & $<1$ \\
\hline
\end{tabular}

Values are Means $\pm S D, n=3$, values with different superscripts in the column are significantly $(p \leq 0.05)$ different

Table 1: Colour parameters, Chemical and microbiological properties of probiotic litchi juice drink of the probiotic litchi juice.

as its negative values indicated greenness of the synbiotic juice. The positive values of $\mathrm{b}^{\star}$ represent yellowness and was found highest in the control sample (7.12) followed by the sample $\mathrm{T}_{3}$. The $\mathrm{pH}$ of the juice samples varied significantly, presented in Table 1 . The lowest $\mathrm{pH}$ value was found in $\mathrm{T}_{3}$ with a value of 4.97 , the decrease in the $\mathrm{pH}$ could be attributed to the acidic nature of the gum acacia, followed by $\mathrm{T}_{2}, \mathrm{~T}_{1} \mathrm{~T}_{4}$ and control, in increasing order. The $\mathrm{pH}$ increased non-significantly $(\mathrm{p} \leq 0.05)$ for the samples $\mathrm{T}_{1} \mathrm{~T}_{4}$ and control. The higher values of water activity (Table 1) of the juice was found in the range of 0.98 to 0.99 and did not change significantly with the treatment.

Total soluble solids of the juice are presented in Table 1. For the sample $\mathrm{T}_{1}, \mathrm{~T}_{3}, \mathrm{~T}_{4}$ and control, TSS did not change significantly, however, for the sample $\mathrm{T}_{2}$ it increased slightly to 21.37 which differed from the other samples significantly. The total population of the probiotic bacteria was found well in the range as recommended by the ICMR, New Delhi for any food to be called as probiotic. The results (Table 1) showed that the WPCP in combination with inulin showed significantly $(\mathrm{p} \leq 0.05)$ higher values $8.12 \mathrm{log} \mathrm{cfu} / \mathrm{ml}$ of litchi juice, followed by $\mathrm{T}_{4}(7.42 \log \mathrm{cfu} / \mathrm{ml}), \mathrm{T}_{3}(7.26 \log \mathrm{cfu} / \mathrm{ml})$ and $\mathrm{T}_{1}(6.9 \log \mathrm{cfu} /$ $\mathrm{ml}$ ). The data suggest that inulin had a positive effect on the protection of $L$. casei 359 during the encapsulation process, probably because it acted as a thermoprotector for the cells undergoing the drying process $[25,30]$. Lian et al. [30] reported that besides difference in chemical characteristics, the encapsulating agents have different physical properties. Therefore, it is reasonable to expect that the different prebiotics tested in this study may exert different degrees of protective effect on the entrapped cells of a test organism when subjected to heat inactivation during spray drying and, thus, take survival of L. casei 359 to a different level. Moreover, according to Ananta et al. [31], since the effectiveness of probiotic consumption on human health is related to their viability, it is of utmost importance to not only minimize cell death during the spray drying process but also to ensure minimal loss of viability of the microencapsulated bacteria during storage. This study indicates that WPCP with inulin encapsulated microcapsules can provide tolerance to probiotic cells.

The steady state rheology of the symbiotic litchi juice (Table 2) was performed at two temperatures $10^{\circ} \mathrm{C}$ and $20^{\circ} \mathrm{C}$. The flow behaviour index $(\mathrm{n})$ of all the samples was observed to be less than one $(<1)$ for both Power-law model and Herschel-Bulkley model which justified shear thinning behaviour the samples. Depending upon the adjacent $\mathrm{R}^{2}$ value Herschel-Bulkley model was found to be best fitted model in all of samples.

FTIR spectroscopy of the probiotic litchi juice are presented in Figure 2. In all the samples, the appearance of the broad band at around 
Citation: Prakash KS, Bashir K, Mishra V (2017) Development of Synbiotic Litchi Juice Drink and its Physiochemical, Viability and Sensory Analysis . J Food Process Technol 8: 708. doi: 10.4172/2157-7110.1000708

Page 4 of 6

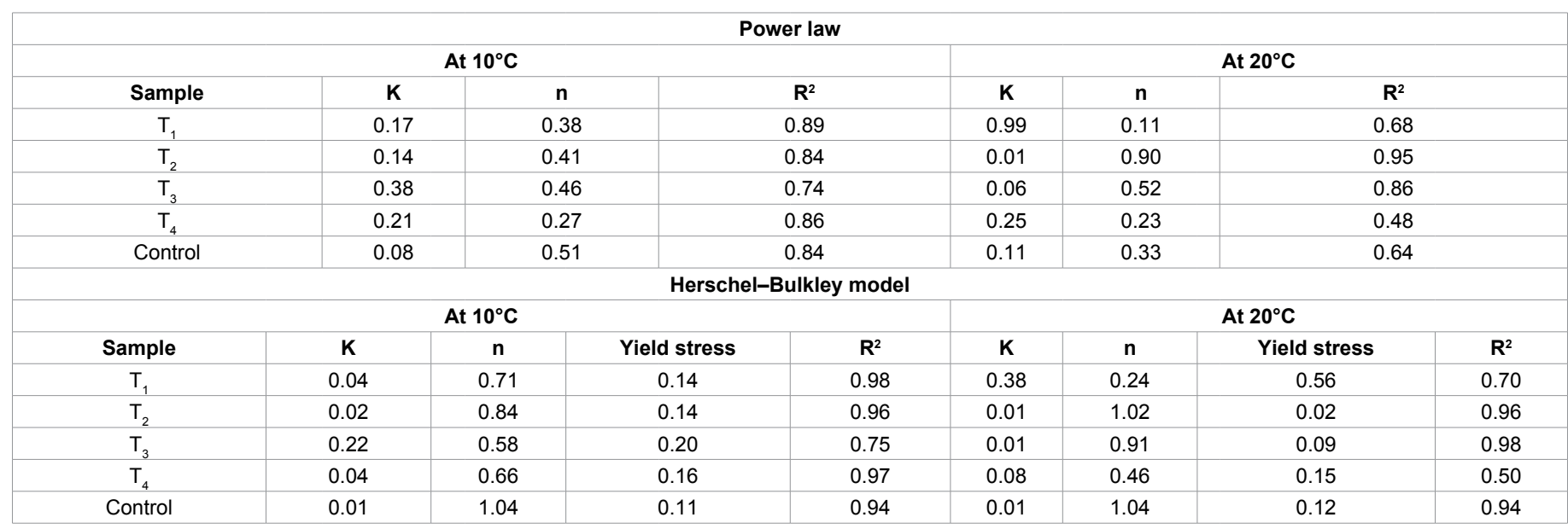

Table 2: Steady state rheology.

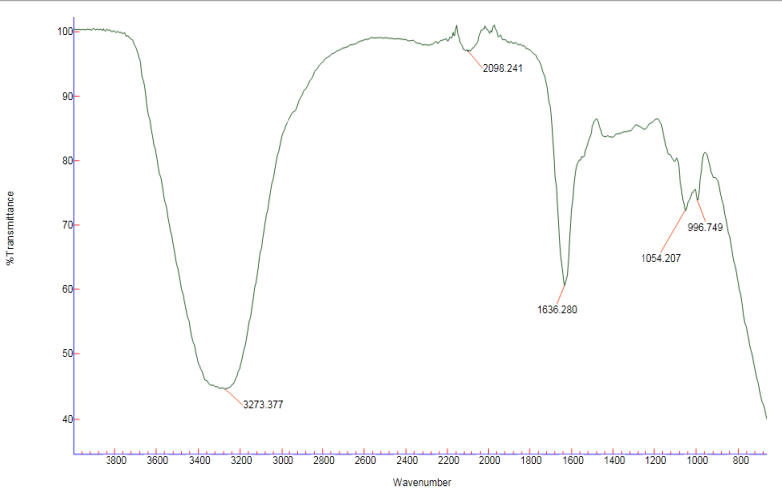

$T_{1}$

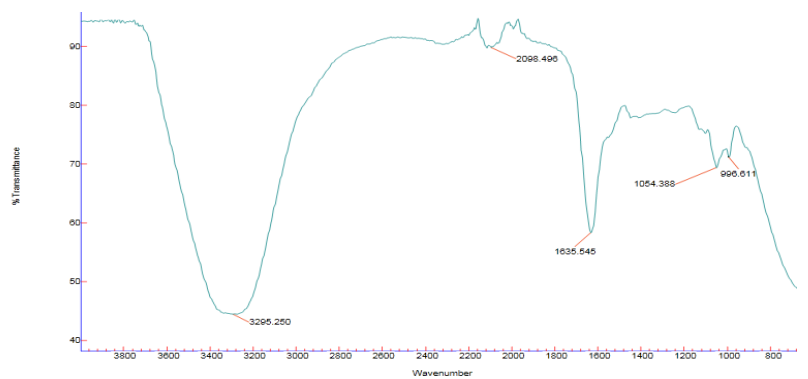

$T_{3}$

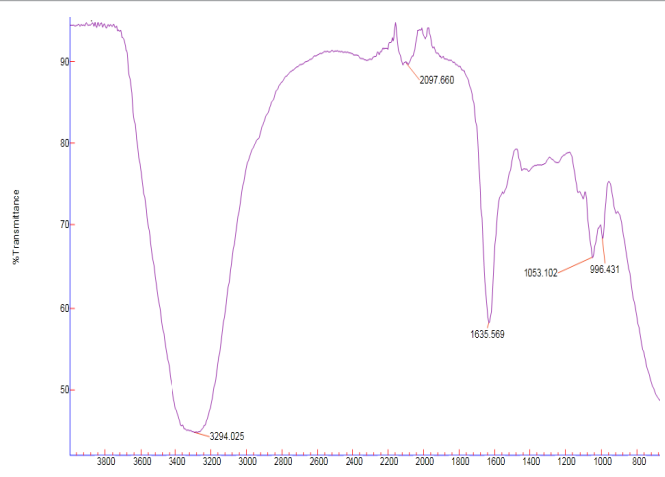

$\mathrm{T}_{2}$

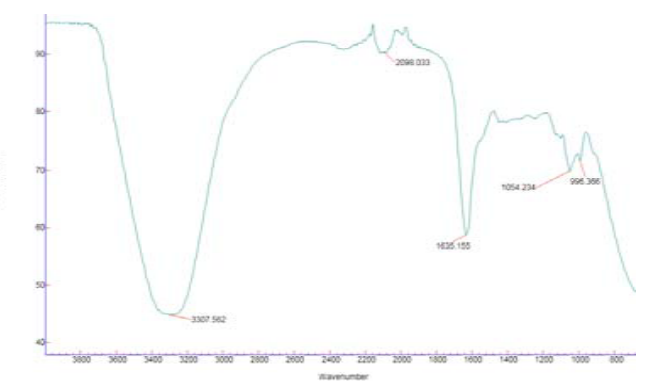

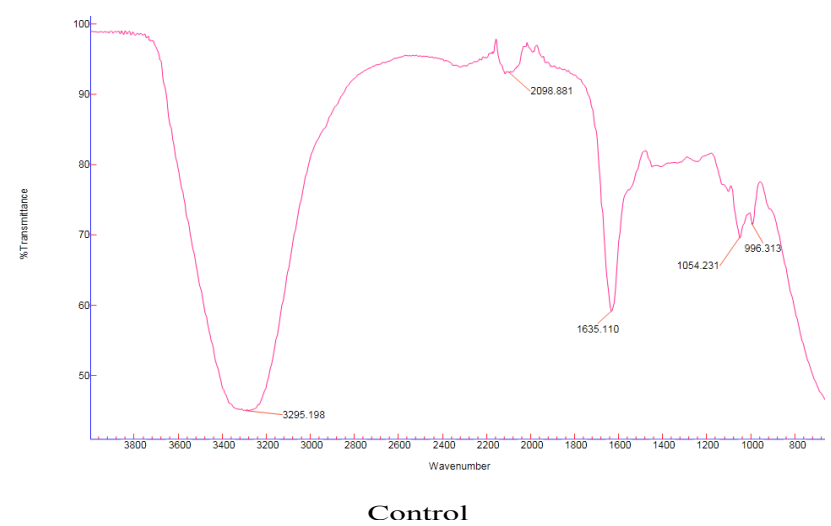

Figure 2: FTIR of synbiotic litchi juice drink. 


\begin{tabular}{|c|c|c|c|c|c|c|}
\hline \multirow{2}{*}{\multicolumn{2}{|c|}{ Sensory quality attributes of samples }} & \multicolumn{5}{|c|}{ Sensory scale factor } \\
\hline & & \multirow{2}{*}{$\begin{array}{c}\text { Not Satisfactory } \\
0\end{array}$} & \multirow{2}{*}{$\begin{array}{c}\text { Fair } \\
2\end{array}$} & \multirow{2}{*}{$\begin{array}{c}\text { Medium } \\
5\end{array}$} & \multirow{2}{*}{$\begin{array}{c}\text { Good } \\
4\end{array}$} & \multirow{2}{*}{$\begin{array}{c}\text { Excellent } \\
0\end{array}$} \\
\hline \multirow{5}{*}{ Colour } & T1 & & & & & \\
\hline & $\mathrm{T} 2$ & 0 & 1 & 3 & 3 & 4 \\
\hline & T3 & 3 & 4 & 3 & 1 & 0 \\
\hline & T4 & 0 & 1 & 5 & 4 & 1 \\
\hline & $\mathrm{C}$ & 1 & 4 & 4 & 2 & 0 \\
\hline \multirow{5}{*}{ Taste } & T1 & 1 & 3 & 5 & 2 & 0 \\
\hline & T2 & 0 & 2 & 6 & 2 & 1 \\
\hline & T3 & 2 & 4 & 4 & 1 & 0 \\
\hline & T4 & 0 & 4 & 5 & 2 & 0 \\
\hline & $C$ & 3 & 5 & 2 & 1 & 0 \\
\hline \multirow{5}{*}{ Aroma } & $\mathrm{T} 1$ & 2 & 4 & 3 & 2 & 0 \\
\hline & T2 & 1 & 3 & 5 & 1 & 1 \\
\hline & T3 & 1 & 5 & 3 & 2 & 0 \\
\hline & $\mathrm{T} 4$ & 2 & 2 & 5 & 2 & 0 \\
\hline & $\mathrm{C}$ & 3 & 3 & 4 & 1 & 0 \\
\hline \multirow{5}{*}{ Mouthfeel } & $\mathrm{T} 1$ & 2 & 4 & 3 & 2 & 0 \\
\hline & $\mathrm{T} 2$ & 0 & 2 & 5 & 1 & 3 \\
\hline & T3 & 2 & 6 & 2 & 1 & 0 \\
\hline & $\mathrm{T} 4$ & 0 & 3 & 5 & 2 & 1 \\
\hline & C & 3 & 4 & 3 & 1 & 0 \\
\hline \multirow{4}{*}{$\begin{array}{l}\text { Sensory quality attributes } \\
\text { litchi juice in general }\end{array}$} & Colour & 1 & 2 & 3 & 3 & 2 \\
\hline & Taste & 0 & 2 & 1 & 3 & 5 \\
\hline & Aroma & 1 & 2 & 2 & 4 & 2 \\
\hline & Mouthfeel & 2 & 1 & 3 & 4 & 1 \\
\hline
\end{tabular}

Table 3: Sum of sensory scores of judges of quality attributes of litchi juice of samples and quality attributes of litchi juice in general.

$3300 \mathrm{~cm}^{-1}$ is due to $\mathrm{O}-\mathrm{H}$ stretching and a small band at $2100 \mathrm{~cm}^{-1}$ is due to $\mathrm{C}-\mathrm{H}$ stretching. The sharp band at $1635 \mathrm{~cm}^{-1} \mathrm{can}$ be ascribed to $\mathrm{H}-\mathrm{O}-\mathrm{H}$ vibrations, $\mathrm{C}=\mathrm{O}$ stretching vibrations of amide $\mathrm{I}$ band, $\mathrm{C}-\mathrm{N}$ stretching and $\mathrm{N}-\mathrm{H}$ bending vibrations of amide II band. A small band at $1054 \mathrm{~cm}^{-1}$ was ascribed to stretching of $\mathrm{C}-\mathrm{O}-\mathrm{H}$ and the band at 996 $\mathrm{cm}^{-1}$ was attributed to the coupling of $\mathrm{C}-\mathrm{O}, \mathrm{C}-\mathrm{O}-\mathrm{C}, \mathrm{O}-\mathrm{H}$ and $\mathrm{C}-\mathrm{C}$ bonds. Denaturation of whey protein showed no marked difference for the band in the region between $1600 \mathrm{~cm}^{-1}$ and $1700 \mathrm{~cm}^{-1}$ [32-35]. FTIR analyses showed that the whey protein, inulin gum acacia and oligofructose were retained as such in the microcapsules after spray drying.

\section{Sensory evaluation}

Similarity values and overall ranking of litchi juice samples: Table 3 shows the response sheets from eleven panellists summed up to get the sums of sensory scores for quality attributes of litchi juice samples and those of quality attributes of litchi juice in general respectively. For Sample 1 (T1), similarity values under "Not satisfactory," "Fair," "Satisfactory," "Good," "Very Good" and "Excellent" were 0.106, 0.493, $0.772,0.593,0.183$ and 0.004 respectively. The highest similarity value, 0.772 was under the "Satisfactory" category; this implied that the overall quality of Sample 1 was "Satisfactory". Proceeding in the same fashion, the overall quality of Samples 2 (T2) was good and sample 3 (T3) and sample 5 (C) was "Fair", while that of Sample 4 (T4) was "Satisfactory". However, within samples 1 and 4 which were "Satisfactory", Sample 2 (0.761) was best. The order of the samples is;

Sample 2 (Good) $>$ Sample $1 \quad$ (Satisfactory) $>$ Sample 4 (Satisfactory) $>$ Sample 5 (Fair) $>$ Sample 3 (Fair)

Ranking of quality attributes of litchi juice in general: For different type of food, quality attributes play an important role, so in the case of litchi juice colour, taste, aroma and mouthfeel were chosen. For colour similarity values under "Not at all necessary," "Somewhat necessary,"
"Necessary," "Important," "Highly important" and "Extremely important" were $0,0.052,0.443,0.789,0.311$ and 0 respectively. The highest similarity value, 0.789 was under the "Important" category so, the quality attributes of colour was "Important". Same for other quality attributes of litchi juice in general taste, aroma and mouthfeel comes under category with similarity value were Highly important (0.701), Important (0.689) and Necessary (0.647) respectively. The overall ranking of the quality attributes of litchi juice in general is;

Taste (Highly important) >Color (Important) $>$ Aroma (Important) $>$ Mouthfeel (Necessary)

\section{Conclusion}

It is important that new non-dairy carriers of probiotics be studied so that range of such functional foods can be enhanced. A synbiotic litchi juice drink was successfully produced by encapsulating the probiotic cells of $L$. casei 359 . The survivability results showed that probiotic trapped in WPCP + inulin acted as excellent protectant for the microorganism. The rheological properties suggest the shear thinning behaviour of the juice drink. Sensory scores as analysed by fuzzy logic indicated the higher acceptability for sample containing inulin.

\section{References}

1. FAO/WHO (2002) Guidelines for the evaluation of probiotics in food. Report of a joint FAO/WHO working group on drafting guidelines for the evaluation of probiotics in foods. London ON, Canada.

2. Mishra V, Prasad DN (2005) Application of In-vitro methods for selection of potential Lactobacillus casei strains as Probiotic. Int J Food Microbiol 103: 109-115.

3. Mishra V, Shah C, Mokashe N, Chavan R, Yadav H, et al. (2015) Probiotics as potential antioxidants: A Systematic Review. J Agri Food Chem 63: 3615-3626.

4. Doleyres $Y$, Lacroix $C$ (2005) Technologies with free and immobilised cells for probiotic bifidobacteria production and protection. Int Dairy J 15: 973-988.

5. Lee YK, Salminen S (1995) The coming to age of probiotics. Trend Food Sci Technol 6: 241-245. 
Citation: Prakash KS, Bashir K, Mishra V (2017) Development of Synbiotic Litchi Juice Drink and its Physiochemical, Viability and Sensory Analysis . J Food Process Technol 8: 708. doi: 10.4172/2157-7110.1000708

6. Corcoran BM, Stanton C, Fitzgerald GF, Ross RP (2005) Survival of probiotic lactobacilli in acidic environments is enhanced in the presence of metabolizable sugars. Appl Environ Microbiol 71: 3060-3067.

7. Mortazavian AM, Ghorbanipour S, Mohammadifar MA, Mohammadi M (2011) Biochemical properties and viable probiotic population of yogurt at different bacterial inoculation rates and incubation temperatures. Phil Agri Sci 94: 155-160.

8. Shah NP (2007) Functional cultures and health benefits. Int Dairy J 17: 1262-1277.

9. Tuorila H, Cardello AV (2002) Consumer responses to an off flavour in juice in the presence of specific health claims. Food Qual Pref 13: 561-569.

10. Ermi S, Setyadjit (2015) Development of new product: Rambutan pulpy juice. Procedia Food Sci 3: 413-425.

11. Suomalainen T, Lagstrom H, Matto J, Saarela M, Arvilommi H, et al. (2006) Influence of whey-based fruit juice containing Lactobacillus rhamnosus on intestinal well-being and humoral immune response in healthy adults. Food Sci Technol 39: 788-795.

12. Yoon KY, Woodams EE, Hang YD (2004) Production of probiotic tomato juice by lactic acid bacteria. J Microbiol 42: 315-318.

13. Krasaekoopt K, Chea $P$ (2007) Probiotication of fruit juices using Lactobacillus casei. Faculty of Biotechnology, Assumption University, Bangkok, Thailand.

14. Krasaekoopt W, Pianjareonlap R, Kittisuriyanont K (2008) Survival of probiotics in fruit Juices during refrigerated storage. Thai J Biotechnol 8: 129-133.

15. Pappalardoa, Gioacchino, Luskb, Jayson L (2016) The role of beliefs in purchasing process of functional foods. Food Qual Pref 53: 151-158.

16. Chowdhury T, Das M (2015) Sensory evaluation of aromatic foods packed in developed starch based films using fuzzy logic. Int J Food Studie 4: 29-48.

17. Das H (2005) Food processing operations analysis. Asian Books Private Limited, New Delhi, India.

18. Jaya S, Das H (2003) Sensory evaluation of mango drinks using fuzzy logic. J Sensory Stud 18: 163-176.

19. Rao PK, Das H (2003) Fuzzy logic based optimization of ingredients for production of mango bar and its properties. J Food Sci Technol 40: 576-581.

20. Mukhopadhyay S, Majumdar GC, Goswami TK, Mishra HN (2013) Fuzzy logic (similarity analysis) approach for sensory evaluation of chhanapodo. LWTFood Sci Technol 53: 204-210.

21. Routray W, Mishra HN (2011) Sensory evaluation of different drinks formulated from dahi (Indian yogurt) powder using fuzzy logic. J Food Process Preserv.
22. Singh KP, Mishra A, Mishra HN (2012) Fuzzy analysis of sensory attributes of bread prepared from millet-based composite flours. LWT-Food Scie Technol 48: 276-282.

23. Sinija VR, Mishra HN (2011) Fuzzy analysis of sensory data for quality evaluation and ranking of instant green tea powder and granules. Food Bioprocess Technol 4: 408-416

24. Uprit S, Mishra HN (2002) Fuzzy multi-attribute decision making approach for development and comparison of soy fortified paneer. J Sensory Studie 17: 163176.

25. Fritzen-Freire, Carlise B, Elane PS, Amboni RC, Stephanie PS, et al. (2012) Microencapsulation of bifidobacteria by spray drying in the presence of prebiotics. Food Res Int 45: 306-312.

26. Jafari SM, Assadpoor E, Bhandari B, He Y (2008) Nano-particle encapsulation of fish oil by spray drying. Food Res Int 41: 172-183.

27. Kim SJ, Cho SY, Kim SH, Song OJ, Shin IS, et al. (2008) Effect of microencapsulation on viability and other characteristics in Lactobacillus acidophilus ATCC 43121. LWT-Food Sci Technol 41: 493-500.

28. Adhikari B, Howes T, Bhandari BR, Langrish TAG (2009) Effect of addition of proteins on the production of amorphous sucrose powder through spray drying. J Food Eng 94: 144-153.

29. Rajam R, Anandharamakrishnan C (2015) Microencapsulation of Lactobacillus plantarum (MTCC 5422) with fructooligosaccharide as wall material by spray drying. LWT - Food Sci Technol 60: 773-780.

30. Lian WC, Hsiao HC, Chou CC (2002) Survival of bifidobacteria after spray drying. Int J Food Microbiol 74: 79-86.

31. Ananta E, Volkert M, Knorr D (2005) Cellular injuries and storage stability of spray-dried Lactobacillus rhamnosus GG. Int Dairy J 15: 399-409.

32. Grube M, Bekers M, Upite D, Kaminska E (2002) Infrared spectra of some fructans. J Spectros 16: 289-296.

33. Bagheri L, Madadlou A, Yarmand M, Mousavi ME (2013) Nanoencapsulation of date palm pit extract in whey protein particles generated via desolvation method. Food Res Int 51: 866-871.

34. Anandharamakrishnan C, Rielly CD, Stapley A (2008) Loss of solubility of $\alpha$-lactalbumin and $\beta$-lactoglobulin during the spray drying of whey proteins. Food Sci Technol 41: 270-277.

35. IHB (2013) Indian horticulture database report-2013. Indian Horticulture Board Ministry of Agriculture, Government of India. 